\title{
Regression Analysis-based Chinese Olympic Games Competitive Sports Strength Evaluation Model Research
}

\author{
Guojin Tang* and Jun Li
}

Shandong Sport University, Jinan 250102, Shandong, China

\begin{abstract}
The paper mainly applies a weighted accumulative method to predict Chinese previous Olympic Games medals total amount and analyze golden medals total amount floating change rule. According to analysis, the paper thinks that Olympic Games medals change rule can be predicted from three aspects that are Chinese economic strength, number of Chinese participants and Chinese medals amount changes followed by time. And then it establishes planning model that targets at minimum error amount between predicted value and actual value, by virtue of previous Olympic Games medals data, applying regression equation method, it gets every influence factor correlations with amount of medals; through applying algebraic calculus, it solves every influence factors weights and then gets medals predicted formula. Use the prediction formula, it solves the amount of medals in 2012, and contrasts with actual amount of medals in 2012, tests formula accuracy. Input Olympic Games relevant prediction data in 2016 into formula, and solve Brazil Rio de Janeiro Olympic Games predicted medals amount.
\end{abstract}

Keywords: Economic strength, evaluation model, least square method, sports health.

\section{INTRODUCTION}

Since China's lawful seat in international Olympic Committee was restored in 1979, China attended the 23rd Summer Olympic Games that held in Los Angeles, America in 1984, and gained 15 golden medals at one stroke that realized "zero" breakthrough in Olympic Games golden medal. After that, China has set foot on the road to push Olympic Games development together with people around the world. In Beijing Olympic Games just ended, China sports delegation achieved good results of 51 golden medals, 21 silver medals and 28 copper medals that ranked the top of golden medal table and the top two of medal table [1]. Then, how to remain and strengthen such development trends, let China to continue to maintain a good momentum of more golden medals achieving in strong events and great breakthrough in weak events so that really become members of world athletics sports structure first group, which is a great problem about Olympic Gamed development strategy that needs to serious research. Therefore, predict future Olympic Games performance is one of hot issues that are researched by physical educators all round the world at present, it relates to all countries sports strategies development target establishment and decision-making management [2].

Olympic Games performance is overall reflection of all countries competitive sports strength, is sum total of individual events strength, and meanwhile suffers other countries performances influence and mutual restricts. With time changes, all countries competitive sports strength will also change, China's strong opponent in Olympic GamesAmerica and Russia's competitive sports strength is also constantly changing, therefore analyze and research on them is very necessary [3]. By comparing America, Russia, and China's Olympic Games strength, the clear understanding on China's competitive sports development status can be obtained, and then provide theoretical references for London Olympic Games in 2012, Sochi Winter Olympic Games in 2014 and China's competitive sports healthy development to provide theoretical references for China's Olympic Games decision and let China's Olympic strength to continue to improve [4].

Olympic Games strategy is a long-term stable planning and general plans with targets of striving for good results and winning honor for the country in Olympic Games. Though Olympic Games golden medal is not the whole Olympic Games strategy, it exactly is a quite objective, specific and its important part in Olympic Games strategy. A country sports development is up to many factors, including economic development level, sports investment, sports system, sports science and technology and else. Therefore, establish models to predict Olympic Games performances is beneficial to confirm correct Olympic Games strategies and guide the implementation of the strategies all measures; establish models to measure state sports strength is beneficial to guide China's sports development and let China to continue to keep sports power situation.

Xiong Qian took the 28th and 29th summer Olympic Games obtained medals' countries or regions as samples, researched on countries economic strength, population amount, sports strength, political stable factor, social development extent, country system and host effect as well as others seven factors' influences on the amount of obtained Olympic Games medals [5]. 
Table 1. All sessions' Olympic Games obtained medals amount and influence factors statistical table.

\begin{tabular}{|c|c|c|c|c|c|c|c|}
\hline Year & $\begin{array}{l}\text { GDP one hundred } \\
\text { million Yuan }\end{array}$ & $\begin{array}{l}\text { Per capita } \\
\text { GDP }\end{array}$ & $\begin{array}{c}\text { Amount of golden } \\
\text { medals }\end{array}$ & $\begin{array}{l}\text { Amount of } \\
\text { medals }\end{array}$ & $\begin{array}{c}\text { The number of China's } \\
\text { participants }\end{array}$ & $\begin{array}{c}\text { The number of world } \\
\text { participants }\end{array}$ & $\begin{array}{c}\text { Ratio of the number of } \\
\text { participants }\end{array}$ \\
\hline 1984 & 7208.1 & 695 & 15 & 32 & 225 & 6797 & $3.31 \%$ \\
\hline 1988 & 15042.8 & 1366 & 5 & 28 & 301 & 8465 & $3.56 \%$ \\
\hline 1992 & 26923.5 & 2311 & 16 & 54 & 251 & 9367 & $2.68 \%$ \\
\hline 2000 & 99214.6 & 7858 & 28 & 59 & 331 & 10651 & $3.11 \%$ \\
\hline 2004 & 159878.3 & 12336 & 32 & 63 & 407 & 11099 & $3.67 \%$ \\
\hline 2008 & 300670 & 22640 & 51 & 100 & 639 & 11438 & $5.59 \%$ \\
\hline 2012 & - & - & 35 & 88 & 396 & 10500 & $3.77 \%$ \\
\hline
\end{tabular}

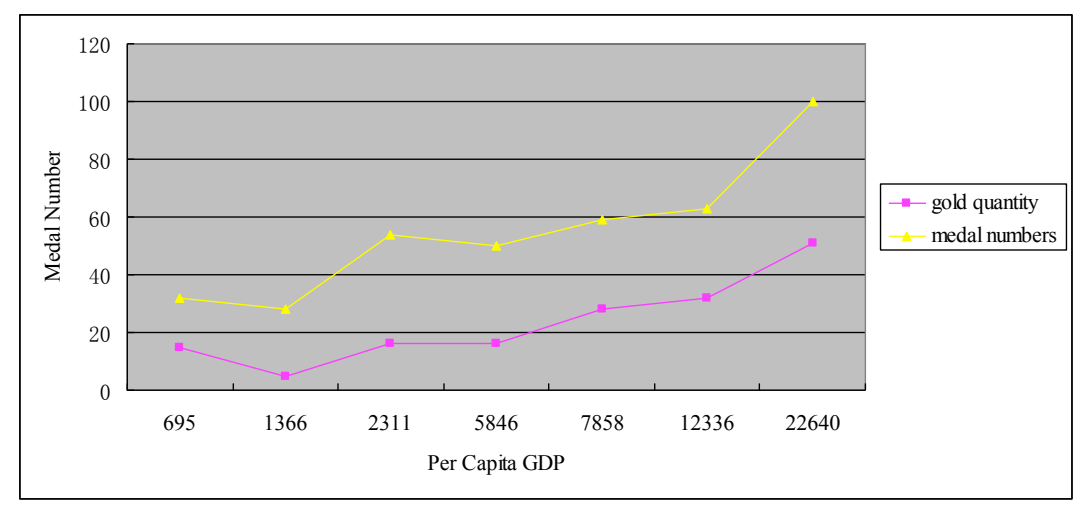

Fig. (1). Broken line figure about the number of medals changes with per capita GDP.

The paper mainly applies a weighted accumulative approach to predict China's previous total amount of Olympic Games medals and analyze total amount of golden medals floating change rules, and predicts amount of China's medals in 2016 Olympic Games and measure China's comprehensive sports strength.

\section{RESEARCH ANALYSES}

Competitive sports has stronger regularities, individual event occasionally doesn't deny necessity of overall development, which also lets our sports events performances prediction to be possible. Due to competitive sports is an asymptotic development process, a country may have breakthrough in one event in one or two sessions Olympic Gamers cycles, but the country competitive sports overall strength substantially raising cannot fulfill in the shortest time, there are very strong correlation between adjacent two sessions' Olympic Games performances. Therefore, we think change of Olympic Games medals is a Markov process.

We think Olympic Games medals change rule can mainly consider from three aspects those are China's economic strength (that is per capita GDP), the number of China's participants, as well as the number of China's medals entire state with time changes. Below are all sessions' Olympic Games' obtained medals amount from year 1984 to 2012 and influence factors statistical Table $\mathbf{1}$.

\section{Economic Factors Impacts on the Number of Medals}

We draw changes that number of medals follow by per capita GDP into broken line Fig. (1).

From Fig. (1), we can see that generally, the number of medals is positive related to per capita GDP. Then, we adopt least square method to calculate one straight line of the highest fitting extent to predict, specific process is as following (due to host effect, it eliminates year 2008 data):

$$
a=\frac{\sum_{i=1}^{6} x i^{*} y i-6 \bar{x} \bar{y}}{\sum_{i=1}^{6} x i^{\wedge} 2-6 \bar{x}^{\wedge} 2} ; b=\bar{y}-a \bar{x}
$$

Data calculation statistical result is as following Table 2:

Input table's data into solution formula, it solves:

$\left\{\begin{array}{l}a=0.0026439 \\ b=34.26554\end{array}\right.$

Therefore, it gets the formula that uses per capita GDP to predict the number of medals as:

$$
Y=0.0026439+34.26554
$$

In the following, we use the formula and get previous Olympic Games medals predicted values, list statistical table as following Table $\mathbf{3}$ : 
Table 2. Each factor data statistical table.

\begin{tabular}{|c|c|c|c|c|}
\hline Year code number $i$ & Per capita GDP $x_{i}$ & Amount of medals $y_{i}$ & $x_{i} * y_{i}$ & $x_{i}^{2}$ \\
\hline 2 & 1366 & 28 & 38248 & 1865956 \\
\hline 3 & 2311 & 54 & 124794 & 5340721 \\
\hline 5 & 7858 & 59 & 463622 & 61748164 \\
\hline 6 & 12336 & 63 & 777168 & 152176896 \\
\hline Summation & ---- & ---- & 1718372 & 255790478 \\
\hline Mean value & 5068.667 & 47.667 & ---- & ---- \\
\hline
\end{tabular}

Table 3. Table of number of medals prediction through per capita GDP.

\begin{tabular}{|c|c|c|c|c|c|c|c|}
\hline Year & $\mathbf{1 9 8 4}$ & $\mathbf{1 9 8 8}$ & $\mathbf{1 9 9 2}$ & $\mathbf{1 9 9 6}$ & $\mathbf{2 0 0 0}$ & $\mathbf{2 0 0 4}$ & $\mathbf{2 0 0 8}$ \\
\hline \hline Year code & 1 & 2 & 3 & 4 & 5 & 6 & 7 \\
\hline $\begin{array}{c}\text { Predicted value of total amount of } \\
\text { medals }\end{array}$ & 36 & 38 & 40 & 50 & 55 & 66 \\
\hline
\end{tabular}

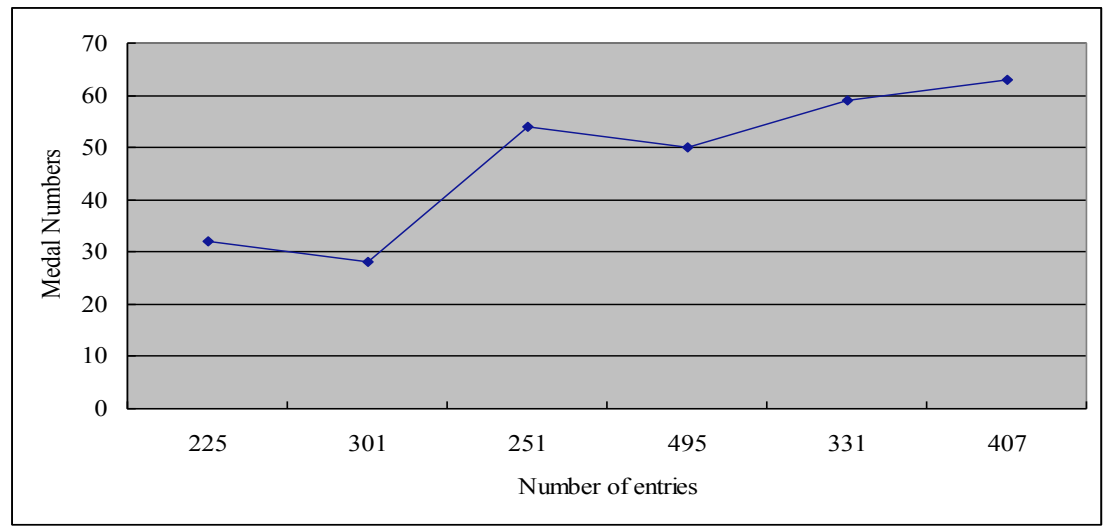

Fig. (2). Broken line figure of medals amount changes by Chinese participants' amount.

Influence of Proportion of Number of Participants on Number of Medals

We create medals amount changes by Chinese participants into figure as following Fig. (2):

From Fig. (2), it is clear that medals amount is increasing with Chinese participants amount increases, similarly we adopt least square method to calculate regression equation, calculation process is as following:

$$
a=\frac{\sum_{i=1}^{6} x i^{*} y i-6 \bar{x} \bar{y}}{\sum_{i=1}^{6} x i^{\wedge} 2-6 \bar{x}^{\wedge} 2} ; b=\bar{y}-a \bar{x}
$$

Data calculation statistical result is as following Table 4:
Input above Table 4 data into formula, it gets:

$\left\{\begin{array}{l}a=0.0630967 \\ b=26.562605\end{array}\right.$

Therefore, use Chinese participants amount to predict, it gets medals amount predicted formula is: $y=0.0630967 x+26.562605$.

According to solved formula, we can get China previous Olympic Games obtained medals amount predicted values from year 1984 to 2008; create these predicted values into statistical table as following Table $\mathbf{5}$ :

\section{Analysis of China Previous Medals Change Rule Fol- lowed by Time}

We draw medals' amount changes with time into following Fig. (3): 
Table 4. Each factor data statistical table.

\begin{tabular}{|c|c|c|c|c|}
\hline Year code $i$ & Per capita GDP $x_{i}$ & Medals amount $y_{i}$ & $x_{i} *_{i}$ \\
\hline \hline 1 & 225 & 32 & 7200 & $x_{i}^{2}$ \\
\hline 2 & 301 & 28 & 8428 & 13554 \\
\hline 3 & 251 & 54 & 24750 & 630601 \\
\hline 4 & 495 & 50 & 19529 & 109561 \\
\hline 5 & 331 & 59 & 25641 & 165649 \\
\hline 6 & 407 & 63 & 99102 & 724462 \\
\hline Summation & --- & --- & - \\
\hline
\end{tabular}

Table 5. Table of previous Olympic Games medals amount through participants' amount predicting.

\begin{tabular}{|c|c|c|c|c|c|c|}
\hline Year & $\mathbf{1 9 8 4}$ & $\mathbf{1 9 8 8}$ & $\mathbf{1 9 9 2}$ & $\mathbf{1 9 9 6}$ & $\mathbf{2 0 0 0}$ & $\mathbf{2 0 0 4}$ \\
\hline \hline Year code & 1 & 2 & 3 & 5 & 5 \\
\hline Medal predicted value $x_{2}$ & 41 & 46 & 42 & 58 & 57 \\
\hline
\end{tabular}

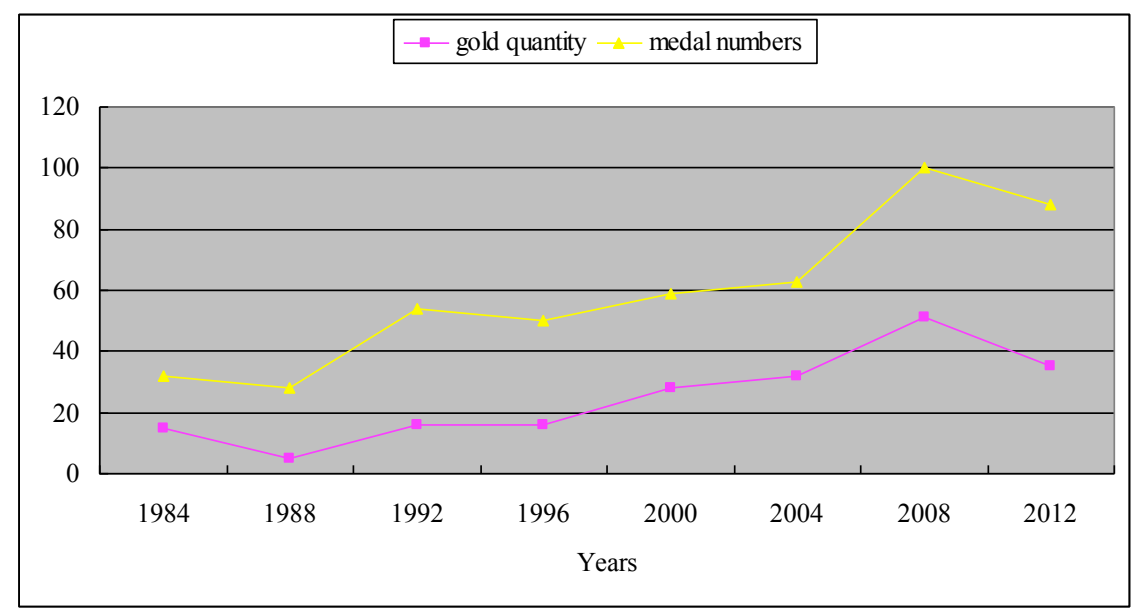

Fig. (3). Change curve figure of medals' amount followed by year.

According to above Table time sequence information, it draws China previous Olympic Games total amount of medals time sequence broken line Fig. (3). By observing time sequence figure, it is clear that time sequence has obvious changing trend, from which data in 2008 has obvious fluctuation, we consider that it has host effects; therefore we eliminate a group of data in 2008 in following analysis. According to intuitional judgment, which is create fitting trend models for previous Olympic Games time sequence attached figure the Olympic Games medals broken line figure.

Establish models:

We select quadric curvilinear trend model:

$Y(t)=a+b t+c t^{2}$
In above equation, three unknown parameters $a, b, c$, according to least square method, it solves time sequence fitting one pieces of trend curve, and lets it to meet following conditions:

$$
\begin{aligned}
& \sum Y=n a+b \sum t+c \sum t^{2} \\
& \sum t Y=a \sum t+b \sum t^{2}+c \sum t^{3} \\
& \sum t^{2} Y=a \sum t^{2}+b \sum t^{3}+c \sum t^{4}
\end{aligned}
$$

According to above Table 6 calculation, it gets $a, b, c$ results as following:

$$
\left\{\begin{array} { l } 
{ 2 8 6 = 6 a + 2 1 b + 9 1 c } \\
{ 1 1 2 3 = 2 1 a + 9 1 b + 4 4 1 c } \\
{ 5 1 7 3 = 9 1 a + 4 4 1 b + 2 2 7 5 c }
\end{array} \quad \left\{\begin{array}{l}
a=18.6 \\
b=10.47 \\
c=-0.5
\end{array}\right.\right.
$$


Table 6. Olympic Games medals quadratic curve calculation table.

\begin{tabular}{|c|c|c|c|c|c|c|c|}
\hline Year & Time mark number $t$ & Observed value $Y_{t}$ & $t^{*} Y_{t}$ & $t^{2}$ & $t^{2} Y_{t}$ & $Y^{3}$ \\
\hline \hline 1984 & 1 & 32 & 32 & 1 & 32 & 1 \\
\hline 1988 & 2 & 28 & 56 & 4 & 112 & 8 & 16 \\
\hline 1992 & 3 & 54 & 162 & 9 & 486 & 27 & 81 \\
\hline 1996 & 4 & 50 & 200 & 16 & 800 & 64 & 256 \\
\hline 2000 & 5 & 59 & 295 & 25 & 1475 & 125 & 625 \\
\hline 2004 & 6 & 63 & 378 & 36 & 2268 & 216 & 1296 \\
\hline & 21 & 286 & 1123 & 91 & 5173 & 441 & 2275 \\
\hline
\end{tabular}

Table 7. Rural sports ground and equipment maintenance.

\begin{tabular}{|c|c|c|c|c|c|c|}
\hline Year & $\mathbf{1 9 8 4}$ & $\mathbf{1 9 8 8}$ & $\mathbf{1 9 9 2}$ & $\mathbf{1 9 9 6}$ & $\mathbf{2 0 0 0}$ & $\mathbf{2 0 0 4}$ \\
\hline \hline Year code & 1 & 2 & 3 & 4 & 5 & 6 \\
\hline Medals total amount predicted value $x_{3}$ & 29 & 38 & 46 & 52 & 58 & 63 \\
\hline
\end{tabular}

Therefore, it gets China Olympic Games medals total amount quadratic curve equation as:

$Y(t)=18.6+10.47 t-0.5 t^{2}$

According to model, it can get previous Olympic Games medal predicted value table as following Table 7 (To get round numbers, we use round off) :

We use the equation to solve total amount of medals in 2012 is: 70 .

\section{Model Solution}

We respectively predict from three aspects, but medal prediction covers so extensive fields, whose actual value cannot be correctly predicted by just one isolated aspect. So, we utilize weighted summation method to synthesize these three aspects to let our predicting work to be more accurate, specifics are as following:

We make statistics of all predicted values as following Table 8:

Input above Table 8 data into equation

$\left\{\begin{array}{l}y=a 1 \bullet x 1+a 2 \bullet x 2+a 3 \bullet x 3 \\ a 1+a 2+a 3=1\end{array}\right.$

It solves:

$\left\{\begin{array}{l}a 1=0.2920355 \\ a 2=0.0796460 \\ a 3=0.6283185\end{array}\right.$

Therefore, we get final medal prediction model formula:

$Y=0.2920355 X_{1}+0.0796460 X_{2}+0.6283185 X_{3}$

\section{Model Test}

Then we will use prediction formula to calculate China obtained total amount of medals in 2012 Olympic Games, and then compare with actual value of China obtained total amount of medals in 2012, test formula accuracy.

Input year $2012 X_{1}=124, X_{2}=52, X_{3}=70$ into formula, it solves predicted value of total amount of medals in 2012 is 84, while actual total amount of medals in 2012 is 88 , there is 4 pieces difference, on a whole, it is supposed that prediction model accuracy is higher.

\section{Model Applications}

Use model to predict unknown China achievable total amount of medals in 2016 Olympic Games, and then it needs Chinese participants' amount in 2016 and Chinese per capita GDP in 2016 these two unknown quantities (Fig. 4). Therefore, we further conduct scientific prediction on the two quantities, specific process is as following:

\section{Prediction on Per Capita GDP in 2016:}

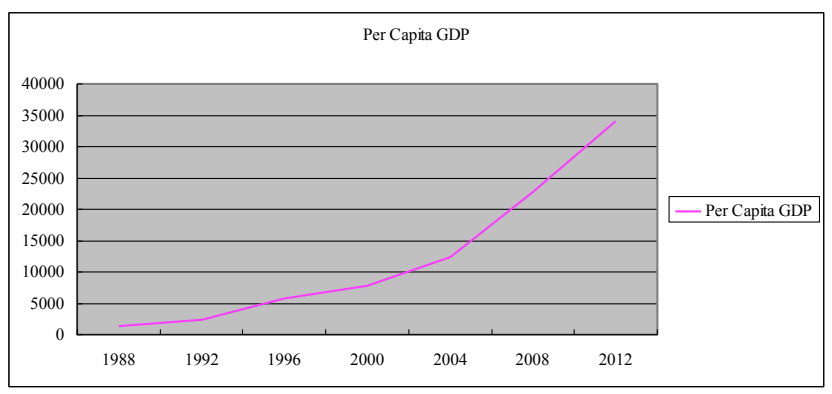

Fig. (4). Curve figure of per capita changes with time.

Above Fig. (4) is per capita GDP changes with time, from the figure, it is clear that figure roughly shows quadratic function type, and then we use quadratic regression equation to predict per capita GDP in 2016, specific process is as following: 
Table 8. Predicted value statistical table.

\begin{tabular}{|l|l|l|l|l|l|l|}
\hline$X_{1}$ & 36 & 38 & 40 & 50 & 55 & 66 \\
\hline$X_{2}$ & 41 & 46 & 42 & 58 & 47 & 52 \\
\hline$X_{3}$ & 29 & 38 & 46 & 52 & 58 & 63 \\
\hline$Y$ & 32 & 28 & 54 & 50 & 59 & 63 \\
\hline
\end{tabular}

Table 9. Prediction table of per capita GDP in 2016.

\begin{tabular}{|c|c|c|c|c|c|c|c|}
\hline Year & Year code $x$ & Per capita GDP $(y)$ & $x^{2}$ & $x^{3}$ & $x^{4}$ & $x y$ & $x^{2} y$ \\
\hline 1984 & 1 & 695 & 1 & 1 & 1 & 695 & 695 \\
\hline 1988 & 2 & 1366 & 4 & 8 & 16 & 2732 & 5464 \\
\hline 1992 & 3 & 2311 & 9 & 27 & 81 & 6933 & 20799 \\
\hline 1996 & 4 & 5846 & 16 & 64 & 256 & 23384 & 93536 \\
\hline 2000 & 5 & 7858 & 25 & 125 & 625 & 39290 & 196450 \\
\hline 2004 & 6 & 12336 & 36 & 216 & 1296 & 74016 & 444096 \\
\hline 2008 & 7 & 22640 & 49 & 343 & 2401 & 158480 & 1109360 \\
\hline 2012 & 8 & 34081 & 64 & 512 & 4096 & 272648 & 2181184 \\
\hline SUB & 36 & 87133 & 204 & 1296 & 8772 & 579178 & 4051584 \\
\hline
\end{tabular}

Table 10. Prediction table of Chinese participants' amount in 2016 Olympic Games.

\begin{tabular}{|c|c|c|c|c|}
\hline Year & Year code $x$ & Amount of Chinese participants $y$ & $x^{2}$ & $x y$ \\
\hline 1984 & 1 & 225 & 1 & 225 \\
\hline 1988 & 2 & 301 & 4 & 602 \\
\hline 1992 & 3 & 251 & 9 & 753 \\
\hline 1996 & 4 & 495 & 16 & 1980 \\
\hline 2000 & 5 & 331 & 25 & 1655 \\
\hline 2004 & 6 & 407 & 36 & 2442 \\
\hline 2012 & 8 & 396 & 64 & 3168 \\
\hline 求和 & --- & --- & 155 & 10825 \\
\hline 平均 & 4.14 & 343.71 & --- & ---- \\
\hline
\end{tabular}

$a \sum_{i=1}^{8} x i^{\wedge} 4+b \sum_{i=1}^{8} x i^{\wedge} 3+c \sum_{i=1}^{8} x i^{\wedge} 2=\sum_{i=1}^{8} x i^{\wedge} 2 \bullet y i$

$a \sum_{i=1}^{8} x i^{\wedge} 3+b \sum_{i=1}^{8} x i^{\wedge} 2+c \sum_{i=1}^{8} x i=\sum_{i=1}^{8} x i \bullet y i$

$a \sum_{i=1}^{8} x i^{\wedge} 2+b \sum_{i=1}^{8} x i+8 c=\sum_{i=1}^{8} y i$

Input Table 9 data into least square method formula, it gets:

$8772 a+1296 b+204 c-4051584=0$

$\{1296 a+204 b+36 c-578178=0$

$204 a+36 b+8 c-87133=0$
By excel MDETERM function, it solves the threevariable linear equation and gets:

$\left\{\begin{array}{l}a=922.48 \\ b=-3871.88 \\ c=4791.77\end{array}\right.$

And further it gets $y=922.48 x^{2}-3871.88+4791.77$

Input $x=9$ and get: $y=44665.95$

Therefore, we get China per capita GDP in 2016 is 44665.95 Yuan 
Prediction on Number of Chinese Participants in 2016 Olympic Games:

We use linear regression to predict Chinese participants' amount:

$$
a=\frac{\sum_{i=1}^{6} x i^{*} y i-6 \bar{x} \bar{y}}{\sum_{i=1}^{6} x i^{\wedge} 2-6 \bar{x}^{\wedge} 2} ; b=\bar{y}-a \bar{x}
$$

Input Table 10 data into formula and calculate, then get:

$$
\left\{\begin{array}{l}
a=241.8 \\
b=24.6
\end{array}\right.
$$

Therefore, Chinese participants' amount prediction formula is:

$$
\begin{aligned}
& Y=24.6 x+241.8 \\
& \text { Input } x=9 \text { and get } Y=439 \\
& \text { Therefore China will have } 439 \text { athletes in } 2016 \text { Olympic } \\
& \text { Games. } \\
& \text { Predict Total Amount of Medals of China in } 2016 \text { Olym- } \\
& \text { pic Games }
\end{aligned}
$$

\section{Predict Total Amount of Medals of China in 2016 Olym- pic Games}

Apply we obtained three prediction formulas, we input per capita GDP in 2016 and participants in 2016 respectively into prediction formulas, and get medal predicted value in 2016

$$
x_{1}=152, x_{2}=54, x_{3}=72
$$

Finally, we input $x_{1}, x_{2}, x_{3}$ in 2016 into $Y=0.2920355 x_{1}+0.0796460 x_{2}+0.6283185 x_{3}$, and get $y=92$, so we get the number of medals in 2016 is 92 . Ratio between golden medals amount and medals amount is around 40\% 50\%, therefore golden medals amount in 2016 Rio de Janeiro should be among 44 46 .

\section{CONCLUSION}

A country or region comprehensive sports performance suffers significant influences from population scale, econom- ic strength, income level, host effect, fondness and focus on sports, system as well as geographic location and other objective factors, which has internal regularities, so it should treat sports performances with correct attitude and not blindly compare oneself with others. To achieve greater results in comprehensive sports, China should adhere to objective law and work from foundation, from which the key points are continuing to strive for improving Chinese overall economic strength and people income level, insisting on the whole nation system, increasing investment to impel nationwide fitness undertaking development, strengthening national fitness consciousness, fostering sports enthusiasm, focusing on healthy national culture. The paper applies weighted accumulative method to predict on China previous Olympic Games medals total amount and analyzes golden medals total amount floating change rule, makes objective evaluation on Chinese comprehensive sports level, which is of certain guiding significance.

\section{CONFLICT OF INTEREST}

The authors confirm that this article content has no conflict of interest.

\section{ACKNOWLEDGEMENTS}

Declared none.

\section{REFERENCES}

[1] L. Cai, and J. Jia, "The role of local government in MICE," Journal of Huazhong University of Science and Technology(Social Science Edition), vol. 21, no. 5, pp. 67-70, 2007.

[2] J. Dong, "Existing mainly problems, reasons and countermeasures about China host mega sport events," Sports \& Science, vol. 33, no. 3, pp. 42-51, 2012.

[3] H, Guo, and Y. Zhu, "Analysis and strategic research on Chinas current sports industry development," Fujian Sports Science and Technology, vol. 20, no. 3, pp. 3-5, 2013.

[4] X. Huang, and W. Zeng, "Research on the commercialized operation of Chinese large physical games with the public welfare," SciTech Information Development \& Economy, vol. 17, no. 21, pp. 137-138, 2007.

[5] L. Zhou, X. Chen, and X. Zhou, "Status and role of government in sport event exhibition industry-taking shanghai as an example," Sports Science Research, vol. 28, no. 4, pp. 48-51, 2007.

(C) Tang and Li; Licensee Bentham Open. 